\title{
Mechanical durability of superhydrophobic surfaces: the role of surface modification technologies
}

\author{
Jing-Hui Zhi ${ }^{1}$, Li-Zhi Zhang ${ }^{1,2 *}$, Yuying Yan $^{3}$, Jie Zhu ${ }^{3}$
}

1. Key Laboratory of Enhanced Heat Transfer and Energy Conservation of Education Ministry, School of Chemistry and Chemical Engineering, South China University of Technology, Guangzhou 510640, China.

2. State Key Laboratory of Subtropical Building Science, South China University of Technology, Guangzhou 510640, China.

3. Fluids \& Thermal Engineering Research Group, Faulty of Engineering, University of Nottingham, Nottingham NG7 2RD, UK

cejinghui.zhi@mail.scut.edu.cn; lzzhang@scut.edu.cn

Corresponding Author: Li-Zhi Zhang*

*E-mail: lzzhang@scut.edu.cn

Tel/fax: 86-020-87114268

\section{Abbreviations}

SS: silica sol;

OA: octadecanoic acid;

HDFS: heptadecafluoro-1,1,2,2-tetrahydrodecyltrichlorosilane;

HTS: hexadecyltriethoxysilane;

TEOS: Tetraethoxysilica;

HMDS: hexamethyldisilazane;

HPW: High purity water;

SEM: scanning electron microscope;

AFM: atomic force microscope;

EDS: Energy dispersion spectroscopy;

XPS: X-ray photoelectron spectroscopy;

SCA: static contact angle;

SA: slide angle.

Abstract: Various surface modification technologies have been used to develop superhydrophobic surface, however their durability has been recognized as the major obstacle for the real applications. Here a quantitative investigation was conducted to evaluate the effects of different surface modification methods on the surfaces' mechanical durability. The superhydrophobic surfaces were prepared by the combination of two surface roughing methods (etching and sandblasting) with chemical modifications with four low surface energy materials: silica sol (SS), octadecanoic acid (OA), heptadecafluoro-1,1,2,2-tetrahydrodecyltrichlorosilane (HDFS) and hexadecyltriethoxysilane (HTS). XPS was used to analyze the elements composition and AFM was used to measure the roughness of the surfaces. The durability of these surfaces was tested by a sandpaper abrasion experiment. The collective results showed that the low surface energy materials had significant effects on the surface roughness, which would then play an important role in the durability of these rough surfaces. The SS modified rough surfaces possessed higher roughness and better durability than the 
surfaces modified by other three low surface energy materials. SS modified rough surfaces could bear 60 cycles of abrasion with $10 \mathrm{~g}$ weights on $1500 \mathrm{CW}$ sandpaper.

Keywords: superhydrophobic; surface roughness; low surface energy material; durability; abrasion; sandblast

\section{Introduction}

As a crucial aspect of interface chemistry, the wettability of a surface shows huge value in fundamental and industrial applications. Since lotus leaves have been found possessing superhydrophobic property, more and more researchers are motivated to study the superhydrophobic phenomenon. When a water droplet can stay on the surface with a static contact angle larger than $150^{\circ}$ and a slide angle less than $10^{\circ}$, the surface is called superhydrophobic surface. These characteristics make the surface achieve certain applicative properties in various fields, including antifogging [1-3], self-cleaning [4, 5], anti-smudge [6, 7], corrosion resistance [8, 9] and anti-frost [10, 11]. In order to achieve superhydrophobic surfaces where the droplets are in Cassie-Baxter state [12], great efforts have been made. Milionis et al. [13] summarized the progress on fabrication, design and understanding of mechanically durable superhydrophobic surfaces. Xue et al. [14] reviewed the recent advances in developing mechanically durable, corrosion-resistant, self-healing and easily repairable superhydrophobic surfaces, which would enable prolonged lifetime of superhydrophobicity for practical applications in the future. The methods prepared superhydrophobic surfaces can be represented by two steps: surface roughing and the subsequent chemical modification by low surface energy materials. They are successful in the fabrication of superhydrophobic surfaces. However, these surfaces are severely restricted by their poor mechanical durability in industrial and practical uses. To enhance their mechanical properties, researchers have done a lot of work. Peng et al. [15] fabricated a rough aluminum surface via a one-step anodization process and a subsequent modification with $1 \mathrm{H}, 1 \mathrm{H}, 2 \mathrm{H}, 2 \mathrm{H}$-perfluorodecyltriethoxysilane (PDES) and stearic acid (STA). They optimized the preparation parameters to fabricate the best rough morphology for the mechanical durability. Zhang et al. [16] introduced micro/nano-pores in PTFE films in order to prepare more durable superhydrophobic surface. To improve durability, Cho et al. [17] proposed a fabrication process in which the dual-scale structures were prepared by combining sandblasting with surface hydroxidion. Further, the roles of the low surface energy materials were studied. Scarratt et al. [18] reported the effects of Teflon AF film wrinkles on the durability, but only one single low surface energy material was considered. Vengatesh et al. [19] investigated the impact of long chain fatty acid, perfluorinated fatty acid and perfluorosulfonicacid-polytetrafluoroethylene copolymer on the superhydrophobicity of anodized aluminum surfaces, but the durability was not mentioned. These studies indicate that a more quantitative analysis is necessary to study the effects of surface modification technologies on the durability, which is the crux for practical applications.

In this paper, the effects of surface modification technologies on durability were quantitatively studied. We used two methods to prepare different roughness surfaces: etching and sandblasting. For the etching method to make rough surface, the micro-bumps and nano-flowers were both acquired by chemical etching. For the sandblasting method to build rough surface, the sandblasting method was used to form micro-bumps followed by chemical etching to form nano-flowers on the micro-bumps. 
1 We also used four low surface energy materials to subsequently modify the rough surfaces: silica sol (SS), octadecanoic acid (OA), heptadecafluoro-1,1,2,2-tetrahydrodecyltrichlorosilane (HDFS) and hexadecyltriethoxysilane (HTS). They were used to coat the rough surfaces through simple solution immersion method. Through combining the two roughing surfaces with the four low surface energy materials, eight kinds of superhydrophobic aluminum surfaces were fabricated. Then through sandpaper abrasion experiments, the effects of the eight modification technologies on the durability were investigated. Meanwhile a pencil hardness test was performed to evaluate the mechanical robustness of the superhydrophobic surfaces like [20]. Long-term exposed test at ambient temperature for 7 months was conducted to estimate the durability of the thin films.

\section{Experimental}

\subsection{Materials}

Pure aluminum plates $[(50 \times 30 \times 0.8 \mathrm{~mm}), 99.99 \%$ of purity] were purchased from Guangzhou HengTai Materials Co., China. Tetraethoxysilica (TEOS), octadecanoic acid (OA) and hexamethyldisilazane (HMDS) were obtained from Guangzhou QianHui Co., China. They were all analytical reagents. Hexadecyltriethoxysilane (HTS) and heptadecafluoro-1,1,2,2-tetrahydrodecy trichlorosilane (HDFS) were bought from Aladdin, ShangHai, China. Methanol, ethanol and acetone were also analytical grade and they were used without any further purification. High purity water (HPW) was prepared by a Purescience water purification system.

\subsection{Modification of Al surfaces}

\subsubsection{Procedure to prepare rough surfaces of Al}

\section{First method for rough surfaces (Method-etching):}

Al plates were cleaned by ultrasonic bath with acetone, ethanol, and HPW for 5 min respectively in sequence. Then they were dried by an air blower. The microstructures of the cleaned Al plates were prepared by chemical etching in $\mathrm{NaClO}$ solution with a volume concentration 1:1 ( $\mathrm{NaClO}$ : $\mathrm{HPW}$ ). The reaction was kept in $30{ }^{\circ} \mathrm{C}$ for $15 \mathrm{~min}$ [21]. After that, the plates were fished out and cleaned by HPW 2 3 times. $0.2 \mathrm{~g} \mathrm{NaOH}$ solid was put in a beaker with $100 \mathrm{ml} \mathrm{HPW}$ to form a solution. It was then heated at $80^{\circ} \mathrm{C}$. The $\mathrm{Al}$ plates with microstructures were dipped in $\mathrm{NaOH}$ solution for 10 min at $80{ }^{\circ} \mathrm{C}$ to obtain nano-flower structures. In the end the plates were cleaned 3 times by HPW, and then dried by the air blower for subsequent use.

\section{Second method for rough surfaces (Method-sandblasting):}

For obtaining micro-bumps structures, Al plates were sprayed by sandblast device with sand particles at a pressure of $6 \mathrm{kgf} \mathrm{\textrm {cm } ^ { 2 }}$. The sizes of the sand particles were 500 mesh [17]. Then the sand blasted Al plates were cleaned by ultrasonic bath with acetone, ethanol, and HPW for 5 min in sequence before building nanostructures. Then they were dried by air blower. The method same as the first one is used to prepare nano-structures. 


\subsubsection{Procedure for the preparation of superhydrophobic modifiers}

Hydrophobic silica sol (SS) was prepared as follows [22]. $30 \mathrm{ml}$ ethanol was added in a beaker. $2.1 \mathrm{ml}$ TEOS was dripped into the ethanol and mixed by vigorously stirring for $10 \mathrm{~min}$. Then $2 \mathrm{ml}$ HMDS was added to the solution slowly. After 30 min mechanical stirring, $3 \mathrm{ml}$ HPW was dropped into the mixture. After $2 \mathrm{~h}$ constant stirring, the mixture formed a transparent sol. The transparent sol solution was placed at least 2 days for aging to form hydrophobic silica sol (SS). SS and ethanol were mixed with a volume concentration of 1:5 for the subsequent use.

Octadecanoic acid (OA) solution was obtained through adding $2 \mathrm{~g}$ octadecanoic acid solid particles into $100 \mathrm{ml}$ ethanol with mechanical stirring at $50{ }^{\circ} \mathrm{C}$ till the solid particles were completely dissolved [23]. Hexadecyltriethoxysilane (HTS) (0.6 g) was dropped into $100 \mathrm{ml}$ methanol [20] to form solution. And heptadecafluoro-1,1,2,2-tetrahydrodecyltrichlorosilane (HDFS) (0.5 ml) was dripped into 100 ml ethanol to form solution[24].

\subsubsection{Procedure for prepared superhydrophobic surfaces}

The nanostructures were prepared by the same means, but the microstructures were made by different means. For convenience, the first method making rough surface was called "etching" for short and the second was called "sandblasting" for short. The samples were defined as "N-M", where $\mathrm{N}$ represented the method to build microstructures and $\mathrm{M}$ meant the modification materials. For example, the sample etching-SS meant that the rough structures were made by the first method and they were then chemically modified by SS. In this paper, 8 kinds of modified superhydrophobic surfaces were made: etching-SS, etching-OA, etching-HTS, etching-HDFS, sandblasting-SS, sandblasting-OA, sandblasting-HTS, and sandblasting-HDFS, respectively.

Etching-SS and sandblasting-SS were made through putting etching and sandblasting into SS for $18 \mathrm{~h}$ at ambient temperature. Their performances were researched after they were taken out and dried. etching-OA and sandblasting-OA were obtained by soaking etching and sandblasting into OA solution for $24 \mathrm{~h}$ at $30{ }^{\circ} \mathrm{C}$. Then the samples were washed by ethanol and HPW for 2 3 times, respectively. After this, the samples were dried in an oven at $80{ }^{\circ} \mathrm{C}$ for $1 \mathrm{~h}$. etching-HDFS and sandblasting-HDFS were prepared through adding etching and sandblasting to HDFS solution for 30 min at $25^{\circ} \mathrm{C}$ followed by keeping them at $140{ }^{\circ} \mathrm{C}$ in an oven for $1 \mathrm{~h}$. etching-HTS and sandblastingHTS were achieved by soaking etching and sandblasting in HTS solution for $1 \mathrm{~h}$ at ambient, and then heating at $130{ }^{\circ} \mathrm{C}$ for $0.5 \mathrm{~h}$ in a oven.

\subsection{Characterization}

The wettability of these samples was measured by a JC2000C1 contact angle system (Shanghai, China) at ambient temperature with a $4 \mu \mathrm{l}$ water droplet. The slide angles were measured by a drop of water released onto the inclined substrate from a defined height. The minimum angle of the inclined surface at which the drop completely rolling off the surface was recorded and that was the sliding angle [25]. Each kind of sample was measured 3 times on different positions and the average value was used. The morphological structures of the samples were observed using scanning electron microscope (SEM, Merlin, LEO1530VP, Germany). Platinum was sprayed onto the samples before observing the morphology in order to enhance the conductivity. The surface topography was captured 
using atomic force microscope (AFM, XE-100, Park, Korea) with a scan size of $5 \mu \mathrm{m} \times 5 \mu \mathrm{m}$. The operating mode of AFM was contacting mode. Energy dispersion spectroscopy (EDS, Inca400, Oxford, England) and X-ray photoelectron spectroscopy (XPS, Axis Ultra DLD, Krato, England) techniques were used to obtain the chemical compositions of the modified samples. The samples were magnified 1000× in EDS measurements. XPS Spectra were recorded using an X-ray source of Al K $\alpha$ radiation with a scan range of $0 \sim 1100 \mathrm{eV}$ binding energy and referenced with respect to adventitious carbon (C 1s: $284.6 \mathrm{eV})$. The chamber pressure was about $5 \times 10^{-9}$ Torr.

\subsection{Durability test}

The mechanical durability of the obtained samples was evaluated via a sandpaper-abrasion method [26] illustrated in Fig. 1. The treated surfaces were placed face-down to the sandpaper $(1500 \mathrm{CW})$. Adding $10 \mathrm{~g}$ weights on the sample, the surface was moved along with a ruler by a force at a speed of $5 \mathrm{~mm} / \mathrm{s}$. The static contact angles was measured after the abrasion test. The test was finished when the contact angle was less than $150^{\circ}$.

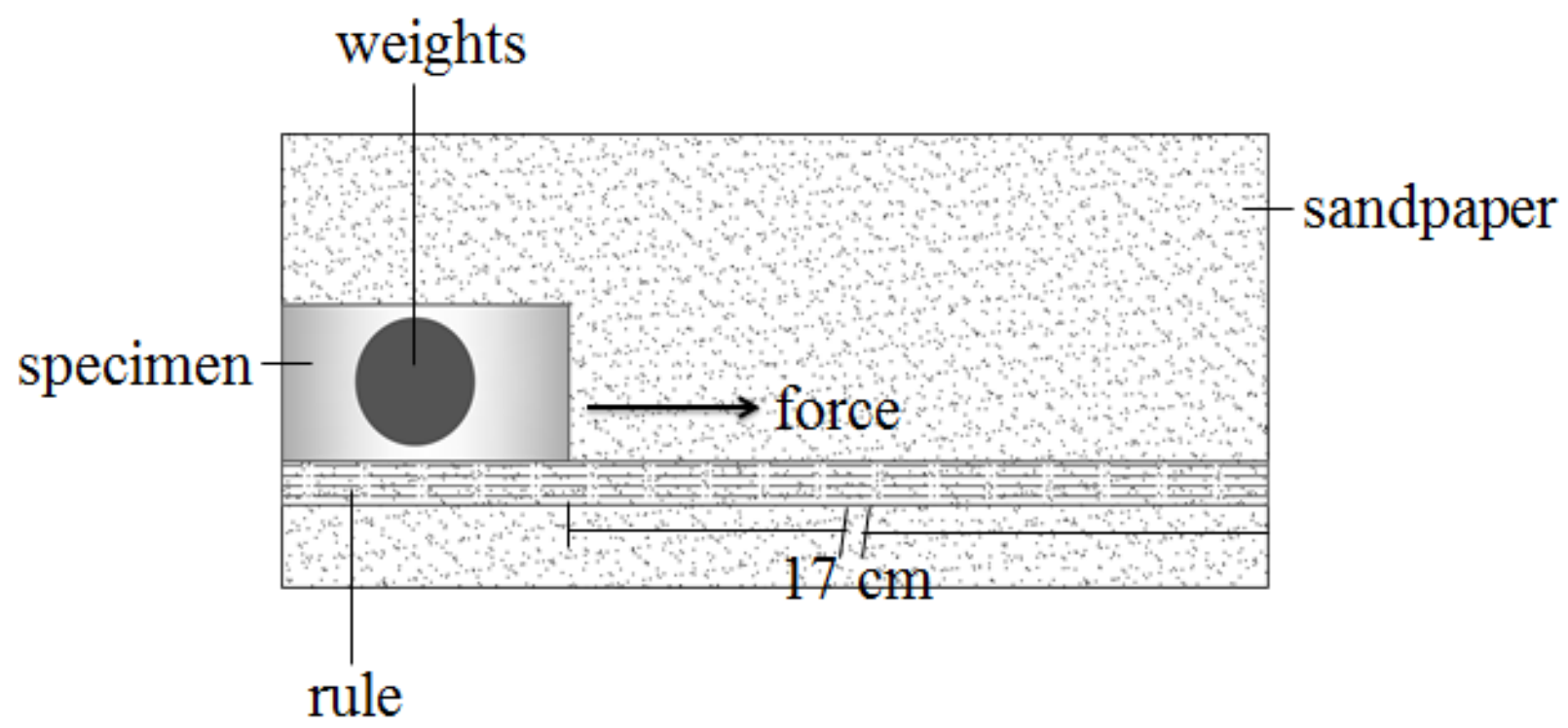

Fig.1. The schematic of sandpaper-abrasion test.

The mechanical robustness of the superhydrophobic surfaces was evaluated through a pencil hardness test on the surfaces before and after exposed at ambient temperature for 7 months. The durability of the thin films in the open air was estimated after exposed the surfaces outside for 7 months.

\section{Results and discussion}

\subsection{Formation of hierarchically structures}

The rough structures were created on the cleaned aluminum surfaces through two methods, namely, two-step chemical etching (etching) and sandblasting combined with wet chemical etching 
(sandblasting). The purpose was to achieve different micro-structures of rough surfaces. The SEM images of bare aluminum and the prepared rough aluminum were provided in Fig. 2.

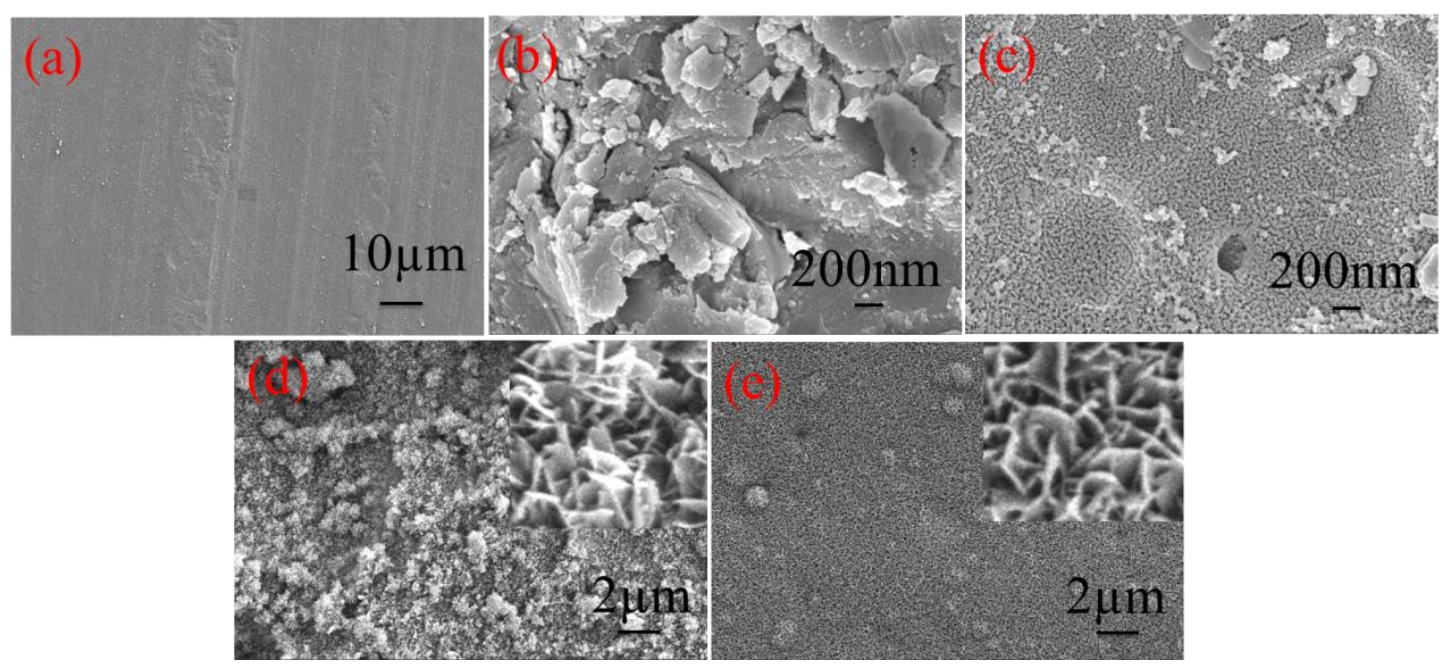

Fig.2. SEM images of (a): bare $\mathrm{Al}$; (b): microstructural $\mathrm{Al}$ obtained by sandblasting; (c): microstructural $\mathrm{Al}$ obtained by $\mathrm{NaClO}$ etching; (d): hierarchical structure obtained by sandblasting combined with wet chemical etching (the amplified picture was inserted into the upper right corner); (e): hierarchical structure obtained by two-step chemical etching (the nanostructures were depicted in the upper right corner).

From the SEM images, it could be seen that the bare Al surface was almost smooth without any rough structures. When it was sandblasted by sand as showed in Fig. 2 (b), the surface morphology changed significantly and it had micro-scale unevenness. Compared to sandblasted surface, when the surface was etched by $\mathrm{NaClO}$ solution as depicted in Fig. 2 (c), small particles appeared on the surface. They were $\mathrm{Al}_{2} \mathrm{O}_{3}$ particles [21], which changed the surface morphology. These two structures of rough surfaces created different roughness. The values of roughness were discussed in AFM measurement. As revealed in Fig. 2 (d), after etched by sodium hydroxide solution, nano-flake structures were formed on the micro-scale structures. Fig. 2 (e) showed similar nano-flake structures as Fig. 2 (d). Two surfaces of different roughness were clearly showed from SEM images. For the surfaces modified by the same low surface energy material, the roughness influenced the durability, which would be discussed in the section of durability test.

\subsection{Surface elemental composition}

The elemental compositions of the fabricated surface samples were analyzed using EDS spectroscopy and X-ray photoelectron spectroscopy (XPS) techniques. In Table 1, the elements acquired on the surfaces could confirm that the surfaces were covered by the low surface energy materials. In order to qualitatively analyze the elemental compositions, XPS was utilized. This spectroscopy was one of the surface sensitive techniques used to provide information on the changes in surface chemistry. XPS survey spectra were displayed in Fig. 3. It could be seen that the rough Al surfaces without low surface energy materials showed only C 1s, O 1s, Al 2p peaks in Fig. 3 (a). However, the C 1 s peak was possibly caused by contaminant carbon [27]. In Fig. 3 (b), it showed the 
1 peak of Si $2 p$ which was attributed to SS. The almost completely disappeared Al $2 p$ peak indicated

2 that SS coated almost all areas of the rough surfaces, so that very little Al could be detected. When

3 the surface suffered physical wears, the SS became the first substance to be abrased and the rough

4 surfaces could be therefore protected. The surface morphology after SS coating could be seen in SEM

5 images in the following section. The intensity of $\mathrm{C} 1 \mathrm{~s}$ peak in Fig. 3 (c) was obviously increased,

6 which confirmed that OA covered on the rough surfaces. The peaks of Si 2p, Cl 2p and F 1s seen in

7 Fig. 3 (d) indicated that HDFS was grafted on the surfaces. And the nearly disappeared $\mathrm{Cl} 2 \mathrm{p}$ peak

8 showed that HDFS hydrolyzed in the ethanol. In Fig. 3 (e), the increased intensity of C 1s peak and

9 the detected Si 2p peak proved that HTS existed on the rough surfaces. These results obtained from

10 XPS survey spectra were in accordance to those from EDS.

\section{Table 1}

13 Atomic percentages of bare $\mathrm{Al}$, rough $\mathrm{Al}$ before and after modification.

\begin{tabular}{|c|c|c|c|c|c|c|}
\hline sample & $\mathrm{C}(\%)$ & $\mathrm{O}(\%)$ & $\mathrm{Al}(\%)$ & $\mathrm{Cl}(\%)$ & $\mathrm{F}(\%)$ & $\mathrm{Si}(\%)$ \\
\hline bare & & 2.93 & 97.07 & & & \\
\hline etching & & 39.02 & 60.98 & & & \\
\hline sandblasting & & 49.03 & 50.97 & & & \\
\hline etching-SS & 23.95 & 36.19 & 38.44 & & & \\
\hline etching-OA & 23.07 & 41.97 & 34.96 & & & \\
\hline $\begin{array}{l}\text { etching- } \\
\text { HDFS }\end{array}$ & 18.91 & 34.83 & 44.05 & 0.76 & 1.06 & 0.38 \\
\hline $\begin{array}{l}\text { etching- } \\
\text { HTS }\end{array}$ & 22.71 & 35.27 & 41.55 & & & 0.47 \\
\hline $\begin{array}{c}\text { sandblasting } \\
\text {-SS }\end{array}$ & 25.15 & 45.16 & 27.15 & & & \\
\hline $\begin{array}{c}\text { sandblasting } \\
-\mathrm{OA}\end{array}$ & 22.56 & 46.65 & 30.79 & & & \\
\hline $\begin{array}{c}\text { sandblasting } \\
\text {-HDFS }\end{array}$ & 16.51 & 45.17 & 36.44 & 0.33 & 1.14 & 0.41 \\
\hline $\begin{array}{c}\text { sandblasting } \\
\text {-HTS }\end{array}$ & 22.47 & 39.18 & 37.75 & & & 0.6 \\
\hline
\end{tabular}



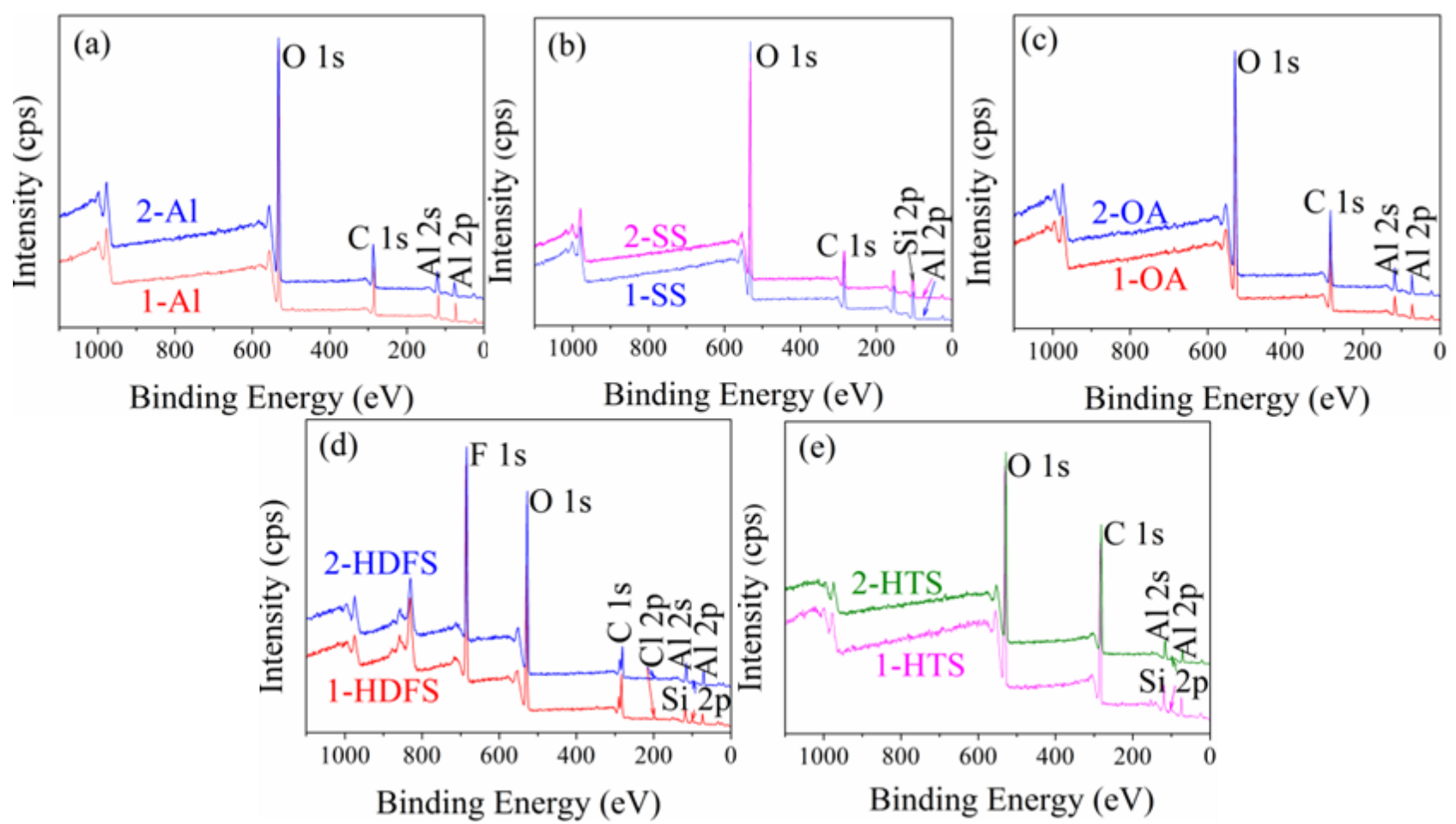

Fig.3. XPS survey spectra of (a): etched rough Al surfaces; (b): rough Al surfaces modified by SS; (c): rough $\mathrm{Al}$ surfaces modified by $\mathrm{OA}$; (d): rough $\mathrm{Al}$ surfaces modified by HDFS; (e): rough $\mathrm{Al}$ surfaces modified by HTS. In the images, "etching" meant that the rough Al surfaces were prepared by chemical etch, and "sandblasting" meant that the rough Al surfaces were made by sandblast.

To get more information in the changes of the surface compositions, XPS deconvoluted spectrum of modified rough surfaces were collected in Fig. 4. Fig. 4 (a) and (b) showed the O 1s and Si 2p peaks of SS. The etching-SS O 1s peak at $532.8 \mathrm{eV}$ and the sandblasting-SS O $1 \mathrm{~s}$ at $532 \mathrm{eV}$ were attributed to $\mathrm{SiO}_{2}[28,29]$. The $\mathrm{Si} 2 \mathrm{p}$ peaks at $103.6 \mathrm{eV}$ and $103.5 \mathrm{eV}$ of etching-SS and sandblasting$\mathrm{SS}$ came from $\mathrm{SiO}_{x}$, respectively [30-32]. These indicated that $\mathrm{SS}$ included many $\mathrm{SiO}_{2}$ particles which could improve the durability of rough surfaces [33]. In Fig. 4 (c), the three peaks of $\mathrm{O} 1 \mathrm{~s}$ at $532.3 \mathrm{eV}$ $(\mathrm{C}-\mathrm{O}), 531.3 \mathrm{eV}(\mathrm{C}=\mathrm{O})$ and $530.2 \mathrm{eV}(-\mathrm{OH})$ [19] were three kinds of valence in OA molecules, which indicated that the valence state of oxygen atom did not change. So the covalent bonds between OA molecules and the rough surface were not formed. The Al 2p peaks of etching-OA and sandblastingOA still at about $74.0 \mathrm{eV}$ which came from $\mathrm{Al}(\mathrm{OH})_{3}$ [34] further explained that the rough $\mathrm{Al}$ surfaces did not react chemically with OA molecules and OA just filled in the pores by physical effect on the rough $\mathrm{Al}$ surface. In Fig. 4 (e) and (g), the $\mathrm{O}$ 1s peaks of HDFS and HTS modified surfaces were all around at $531.6 \mathrm{eV}$, attributing to the -Si-O-Al group [35]. The presence of $\mathrm{Si} 2 \mathrm{p}$ peaks around 101.95 eV in Fig. 4 (f) and (h) confirmed that -C-Si-O group existed [31, 36]. The formed -C-Si-O and -SiO-Al groups illustrated that HDFS and HTS were grafted to the surface with covalent bonds. In most cases, the three methoxyl groups in the HTS molecules were unable to be converted to hydroxyls completely, and incompletely hydrolysed silane molecules could also be grafted to the substrates during the later silanization processes, leading to a large degree of local disorder in the surface layer. So the Si 2 p peak of HTS was thus relatively more variable [37]. The reason for the fluctuating Si $2 p$ peaks of HDFS in Fig. 4 (f) was the same as previously described. 


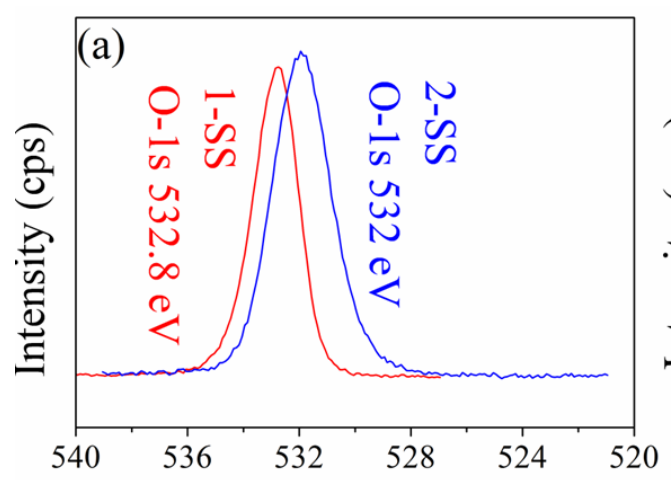

Binding Energy $(\mathrm{eV})$

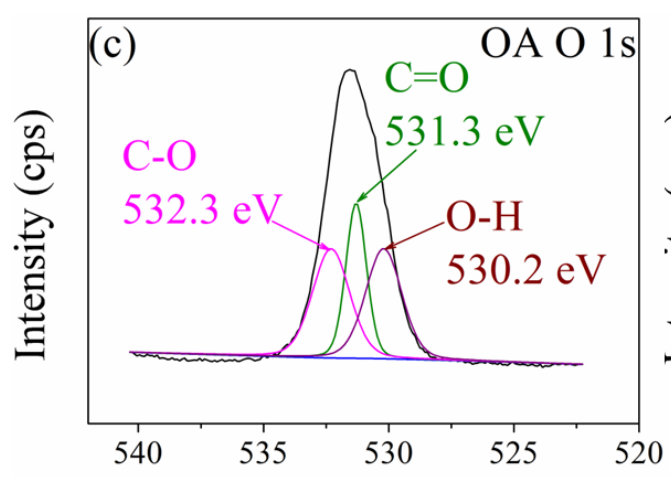

Binding Energy (eV)

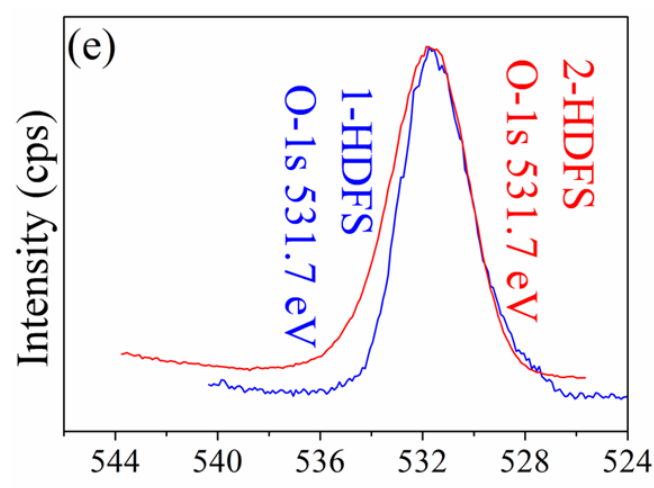

Binding Energy (eV)

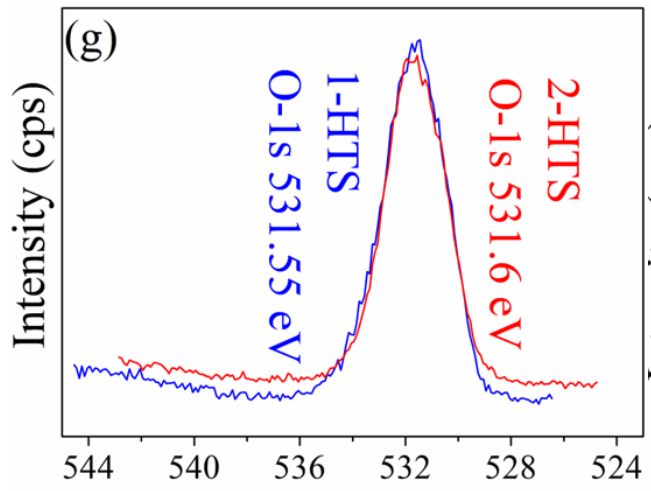

Binding Energy (eV)

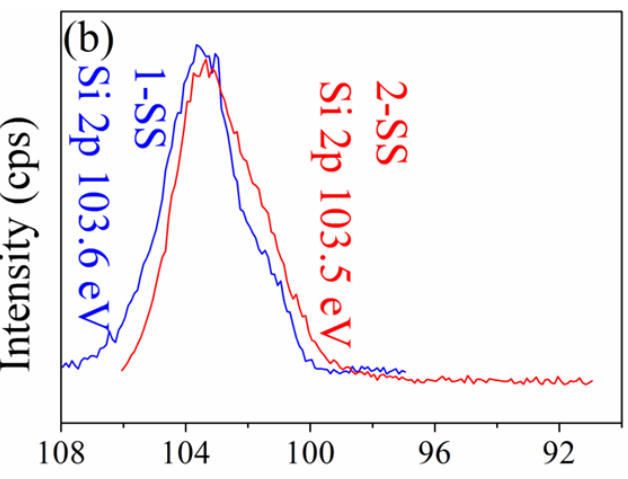

Binding Energy $(\mathrm{eV})$

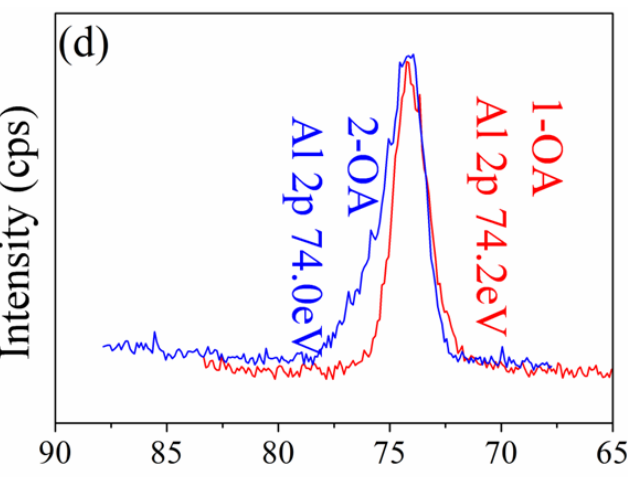

Binding Energy (eV)

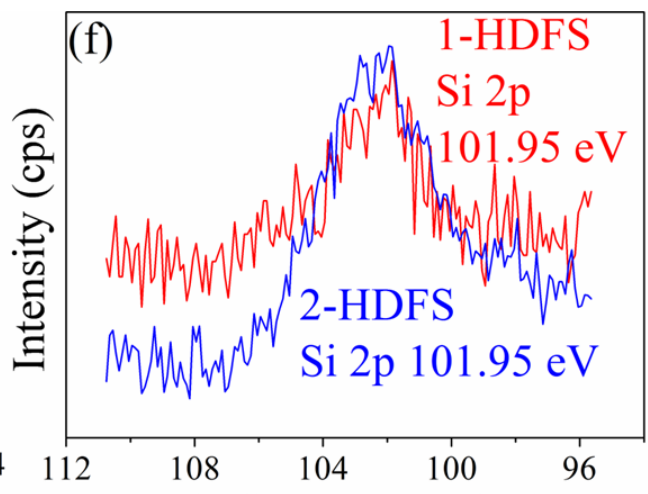

Binding Energy (eV)

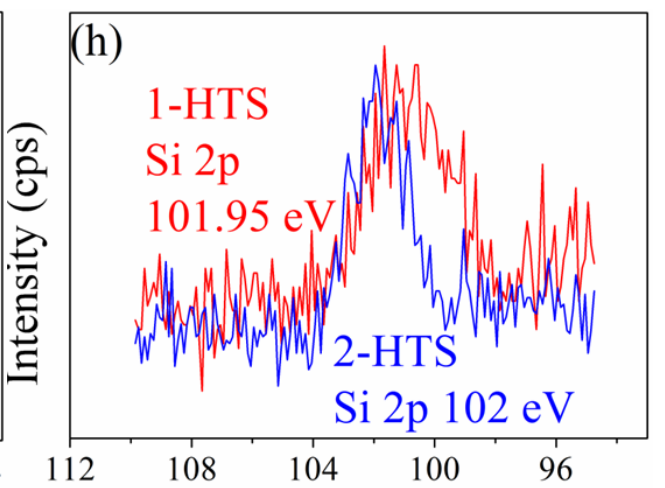

Binding Energy (eV)

Fig.4. Deconvoluted XPS spectra of different chemical modification technologies on the two kinds of rough surfaces (etching and sandblasting). SS: (a) O 1s and (b) Si 2p; OA: (c) O 1s and (d) Al 2p; HDFS: (e) O 1s and (f) Si 2p; HTS: (g) O 1s and (h) Si 2p. 
Since the depth of XPS detection was only $1.5 \mathrm{~nm}$, and the height of SS stacked on the rough surfaces was larger than $1.5 \mathrm{~nm}$, so it's hard to detect whether or not the covalent bonds between the SS and the rough Al surface were formed. The rough surfaces could only be seen from the 3D images of AFM. However, from the routes of SS fabrication, it could be concluded that there were no covalent bonds formed between the SS and the rough $\mathrm{Al}$ surfaces. The $\equiv \mathrm{Si}-\mathrm{O}-\mathrm{Si}\left(\mathrm{CH}_{3}\right)_{3}$ molecules had no active groups to react with $\mathrm{Al}$ surface. The routes of SS fabrication were listed as follows [22]:

$$
\begin{aligned}
& \left(\mathrm{CH}_{3}\right)_{3} \mathrm{SiNHSi}\left(\mathrm{CH}_{3}\right)_{3}+2 \mathrm{H}_{2} \mathrm{O} \rightarrow 2 \mathrm{HO}-\mathrm{Si}\left(\mathrm{CH}_{3}\right)_{3}+\mathrm{NH}_{3} \\
& \mathrm{Si}\left(\mathrm{OCH}_{2} \mathrm{CH}_{3}\right)_{4}+4 \mathrm{H}_{2} \mathrm{O} \rightarrow \mathrm{Si}(\mathrm{OH})_{4}+4 \mathrm{CH}_{3} \mathrm{CH}_{2} \mathrm{OH} \\
& \equiv \mathrm{Si}-\mathrm{OH}+\mathrm{HO}-\mathrm{Si}\left(\mathrm{CH}_{3}\right)_{3} \rightarrow \equiv \mathrm{Si}-\mathrm{O}-\mathrm{Si}\left(\mathrm{CH}_{3}\right)_{3}+\mathrm{H}_{2} \mathrm{O}
\end{aligned}
$$

So the increased durability of SS modified surfaces could only be attributed to the existence of stacked $\mathrm{SiO}_{2}$ inside the surfaces

\subsection{Surface morphological studies}

SEM technique was used to observe the morphologies of surfaces after modified with different low surface energy materials including SS, OA, HDFS and HTS. These materials were introduced particularly to investigate their effects on durability property. Fig. 5 showed the images of rough surfaces modified by hydrophobic materials.

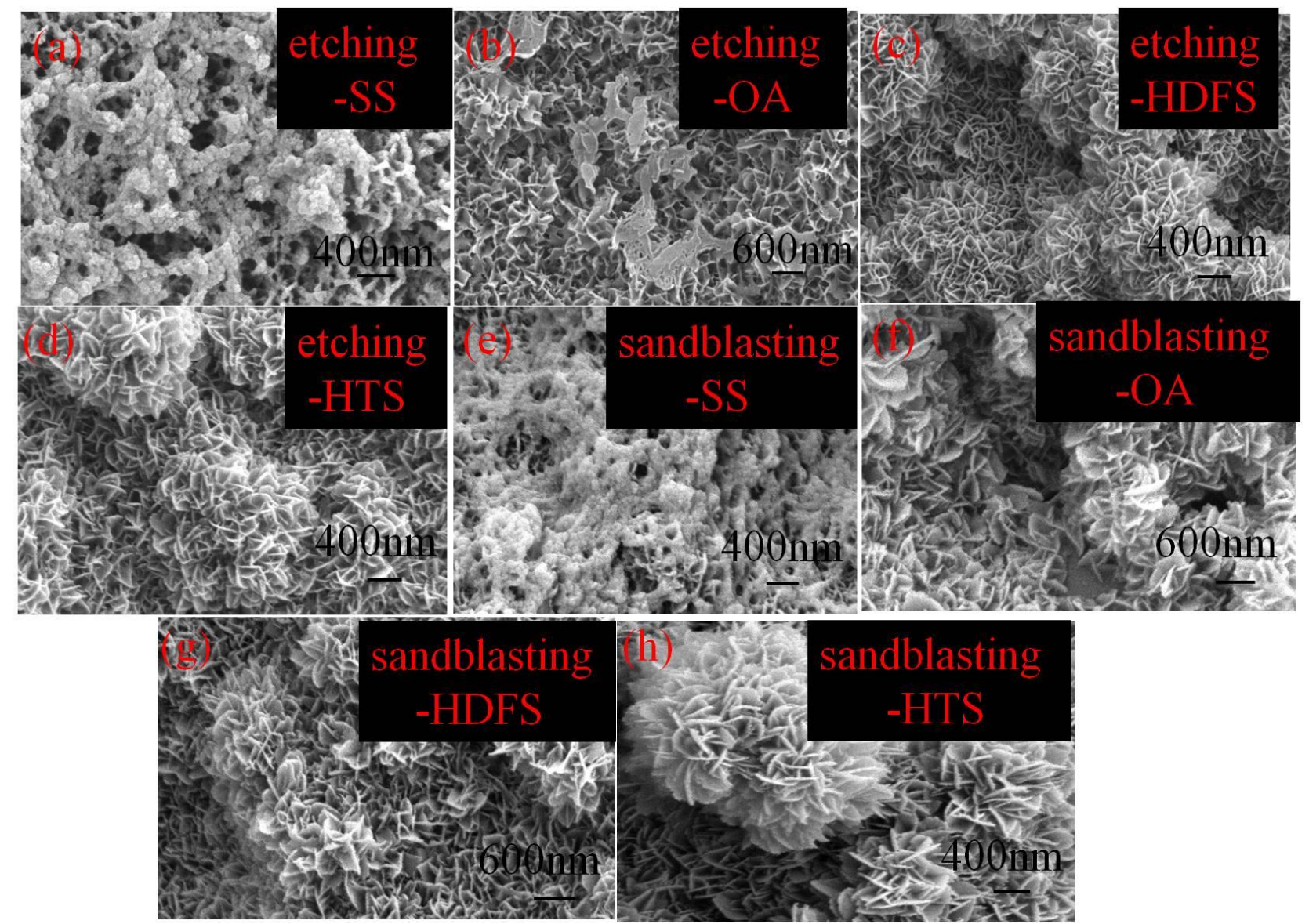

Fig.5. SEM images showing the structures of (a): etching-SS; (b): etching-OA; (c): etching-HDFS; (d): etching-HTS; (e): sandblasting-SS; (f): sandblasting-OA; (g): sandblasting-HDFS; (h): sandblasting- HTS. 
The SEM images were visualized to reveal the results. It could be seen that the surfaces of etching-SS and sandblasting-SS in Fig. 5 (a) and (e) were coated by silica sol with a mountain of $\mathrm{SiO}_{2}$ particles. The SS layer consisted of nanoparticles had very high surface curvature. The nano particle aggregates increased the surface curvature of convex particles, so the contact angles of SS modified surfaces were increased. [38] Thus, even if some part of SS coating was frayed, the remaining particles with very high contact angles would ensure the sample still have high contact angles. In Fig. 5 (b) and (f), the two rough surfaces were modified by OA which just filled in the grooves on the surfaces without any covalent bond. When the surface was rubbed against sandpaper, OA was worn off from surfaces easily, exposing the hydrophilic Al. Water would stick to the surface and non-wettability was lost even though the Cassie state was still stable [39]. Fig. 4 (c) etching-HDFS, (d) etching-HTS, (g) sandblasting-HDFS and (h) sandblasting-HTS showed that HDFS and HTS had no obvious effect on morphologies. It indirectly showed that HDFS and HTS were grafted on the surfaces with covalent bonds. When the rough surfaces modified by HDFS or HTS were frayed, the modified microstructures would defend the surfaces from abrasion, [40] thus the surface could bear a certain degree of abrasion, keeping the surfaces still superhydrophobic.

AFM, a topography observation tool, was used to observe the changes of the surface topography and the roughness of various substrates before and after modification. Fig. 6 and Fig. 7 illustrated the surface topography of Al plates before and after modified by low surface energy materials through plane images and 3D images. From the topographical images in Fig. 6 and Fig. 7, the topography of etching-SS, etching-OA, sandblasting-SS and sandblasting-OA had obviously changed, which was consistent with the SEM images. As shown in the plane images (Fig. 6 (b)), the etching-SS surface was coated with a large number of prills, while the etching-OA surface topography showed in Fig. 6 (c) became smooth without distinct micro-structures. Fig. 6 (d) etching-HDFS and 6 (e) etching-HTS had no evident variations in the structures. AFM 3D images provided more direct evidence of topography changes on the modified Al surfaces, which were outlined in Fig. 6 (i-v) and Fig. 7 (i-v). The values of roughness $\left(R_{\mathrm{q}}\right)$ were calculated by the analysis software of AMF to explain the changes of the rough surfaces and the values were listed in Table 2 . The formula of the analysis software used to calculate the $R_{\mathrm{q}}$ was given in equation (1), where $L$ represented the length of the computational domain in two-dimensional rough surface contour, $y\left(x_{i}\right)$ was the height of the measurement points in two-dimensional rough surface contour, and $n$ was the number of the sampling sites.

$$
R_{\mathrm{q}}=\sqrt{\frac{1}{L} \int_{0}^{L}[y(x)]^{2} d x}=\sqrt{\frac{1}{n} \sum_{i=1}^{n} y\left(x_{i}\right)^{2}}
$$

From the equation (1), the value of $R_{\mathrm{q}}$ was larger when $y\left(x_{i}\right)$ was higher for an equal number of sampling sites. In AFM measurement, all the samples were measured with a scan size of $5 \mu \mathrm{m} \times 5$ $\mu \mathrm{m}$. So it was concluded that the SS modified rough surfaces had the maximum $R_{\mathrm{q}}$ values and the OA modified surfaces had the minimum $R_{\mathrm{q}}$ values. Meanwhile, for the superhydrophobic surfaces modified by the same low surface energy material, the second roughing method had higher $R_{\mathrm{q}}$ values than the first method. So the superhydrophobic surface of sandblasting-SS had the highest $R_{\mathrm{q}}$ values 

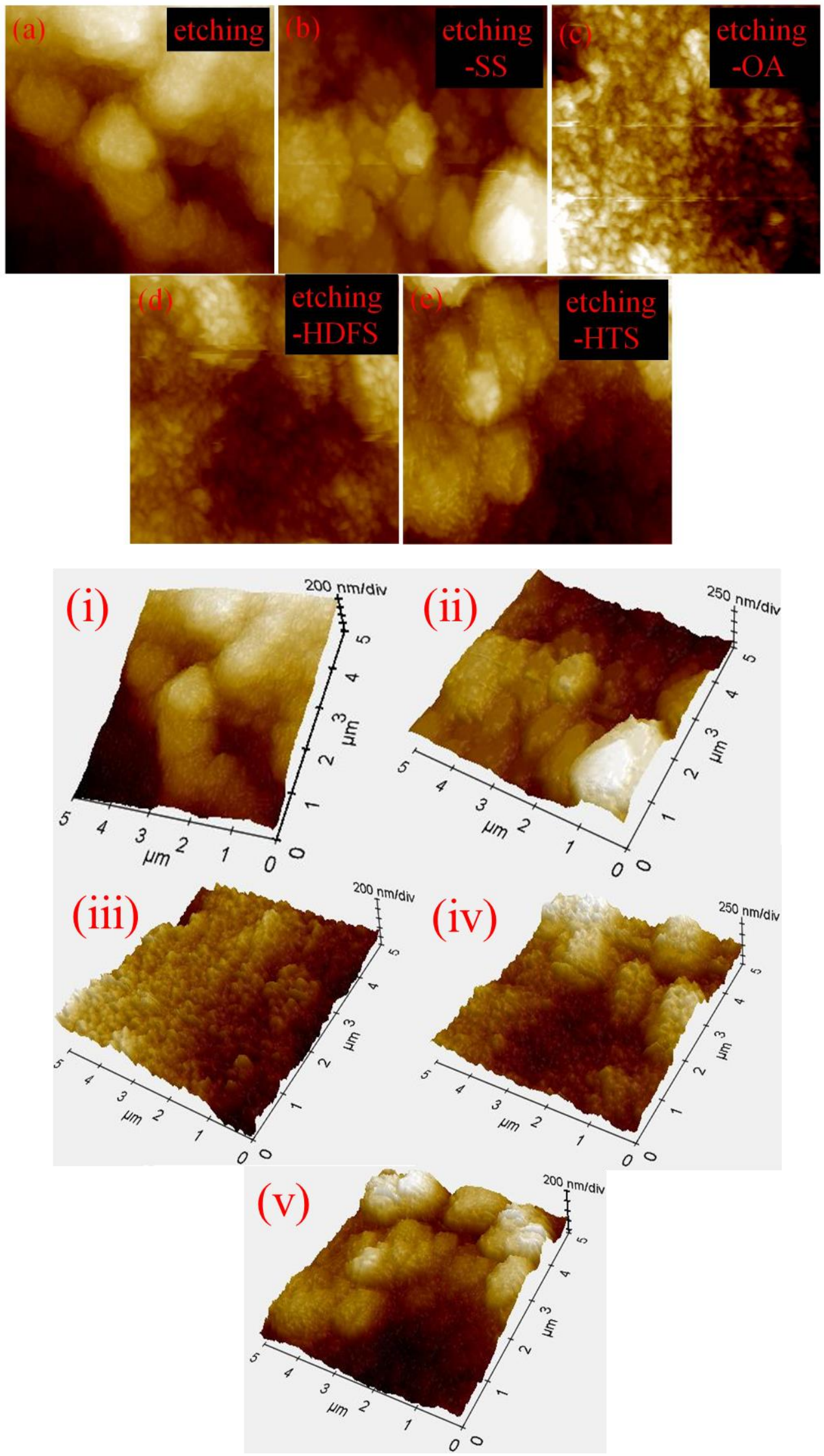

3 Fig.6. AFM plane images and 3D images of the rough $\mathrm{Al}$ surfaces made by etching-method before 4 and after modification. (a) and (i): etching; (b) and (ii): etching-SS; (c) and (iii): etching-OA; (d) and 
1 (iv): etching-HDFS; (e) and (v): etching-HTS. The roughness parameters were achieved by profile 2 extraction of topographical images. Scan area $5 \times 5 \mu \mathrm{m}^{2}$.

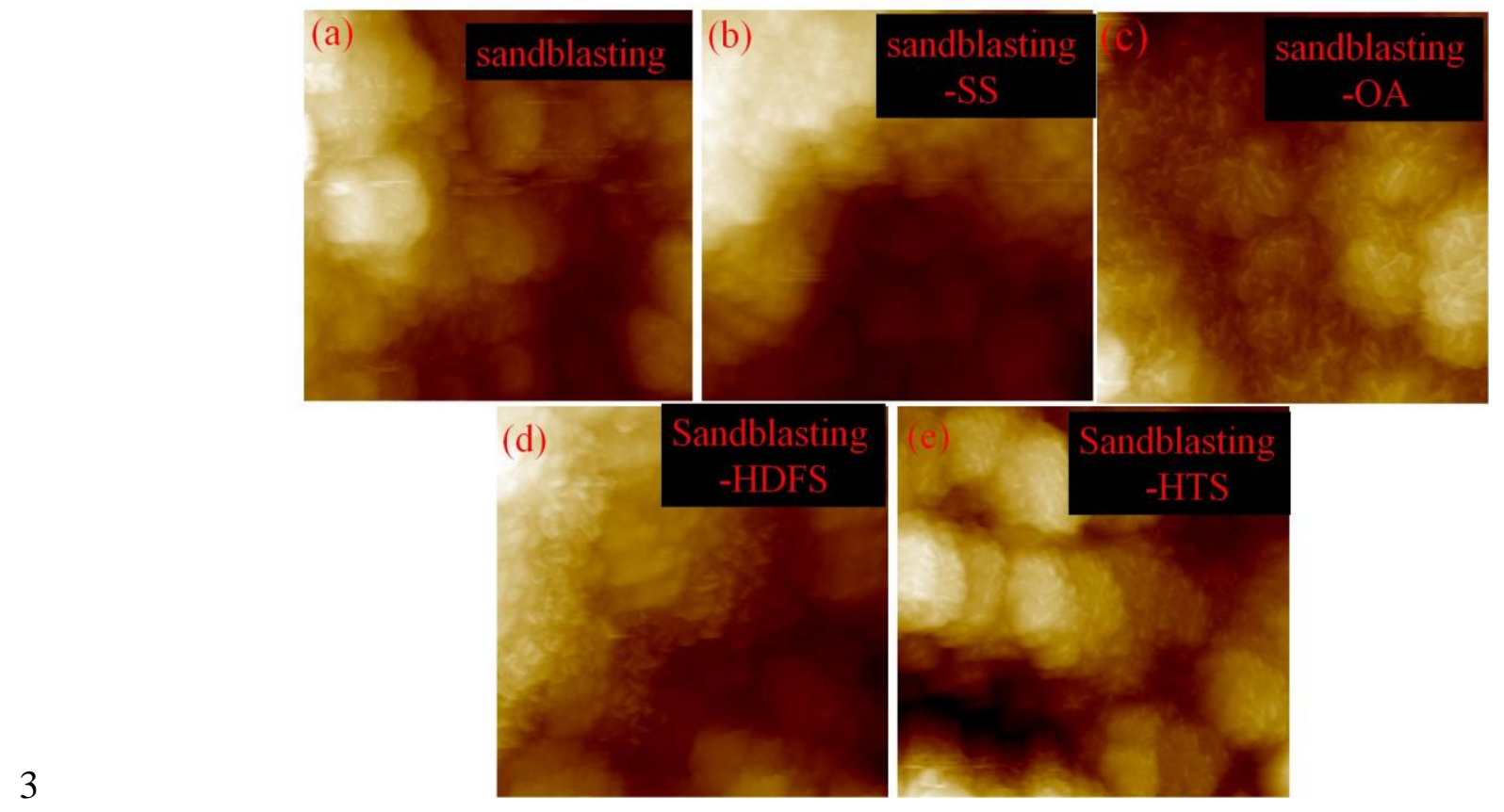

4
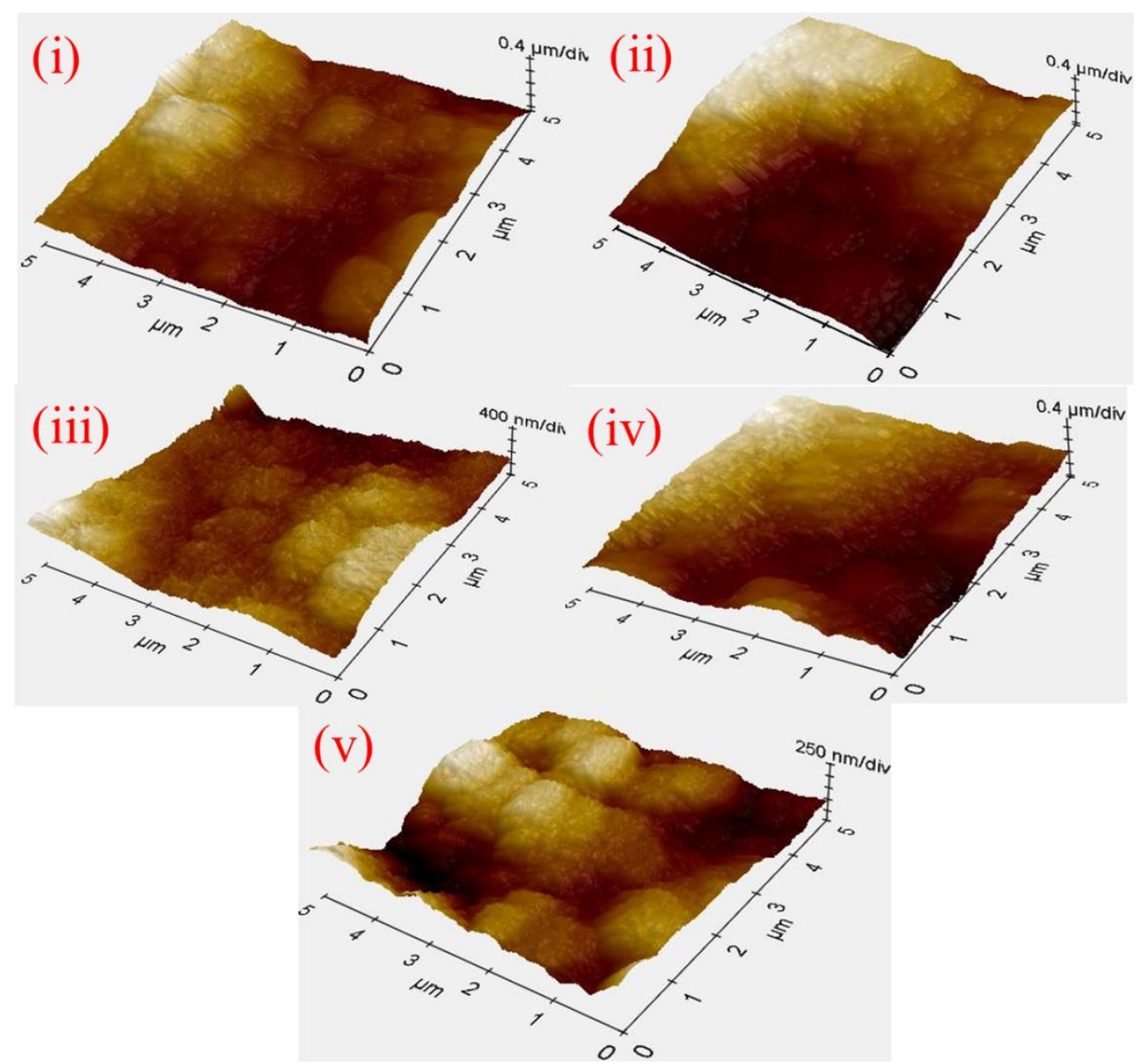

6 Fig.7. AFM plane images and 3D images of the rough Al surfaces made by sandblasting-method 7 before and after modification. (a) and (i): sandblasting; (b) and (ii): sandblasting-SS; (c) and (iii): 
1 sandblasting-OA; (d) and (iv): sandblasting-HDFS; (e) and (v): sandblasting-HTS. The roughness 2 parameters were achieved by profile extraction of topographical images. Scan area $5 \times 5 \mu \mathrm{m}^{2}$.

\section{Table 2}

5 Effects of roughness on wettability and durability.

\begin{tabular}{ccccc}
\hline samples & $R_{q}(\mu \mathrm{m})$ & $\mathrm{SCA}\left(^{\circ}\right)$ & $\mathrm{SA}\left(^{\circ}\right)$ & abrasion times \\
\hline etching & $0.170 \pm 0.014$ & $\backslash$ & $\backslash$ & $\backslash$ \\
etching-SS & $0.212 \pm 0.024$ & $166 \pm 1.6$ & $2 \pm 0.3$ & $35 \pm 5$ \\
etching-OA & $0.152 \pm 0.009$ & $143 \pm 4.3$ & $18 \pm 3.5$ & $\backslash$ \\
etching-HDFS & $0.184 \pm 0.021$ & $159 \pm 1.0$ & $3.5 \pm 1.0$ & $23 \pm 4$ \\
etching-HTS & $0.190 \pm 0.021$ & $153.5 \pm 1.3$ & $3 \pm 1.2$ & $21 \pm 3$ \\
sandblasting & $0.348 \pm 0.026$ & $\backslash$ & 1 & 1 \\
sandblasting-SS & $0.474 \pm 0.054$ & $165 \pm 2.0$ & $2 \pm 0.5$ & $60 \pm 2.5$ \\
sandblasting-OA & $0.245 \pm 0.017$ & $150 \pm 1.5$ & $9 \pm 2.5$ & $4 \pm 2$ \\
sandblasting-HDFS & $0.373 \pm 0.036$ & $158 \pm 2.0$ & $3 \pm 1.1$ & $31 \pm 2$ \\
sandblasting-HTS & $0.364 \pm 0.035$ & $155 \pm 1.8$ & $3.5 \pm 0.8$ & $30 \pm 4$ \\
\hline
\end{tabular}

\subsection{Surface wettability}

In order to describe the wettability of the modified rough surfaces, the static contact angles (SCA) 10 were tested using an optical contact angle instrument. The slide angles (SA) were measured by a drop 11 of water released onto the inclined substrate from a defined height. The minimum angle of inclined 12 surface at which the drop completely rolled off the surface was defined as the sliding angle. Fig. 8 13 displayed the images of SCA on the modified rough Al substrates. The values of SCA, SA and $R_{\mathrm{q}}$ 14 were presented in Table 2. The contact angles of the flat aluminum and the flat layer of each 15 modification were listed in Table 3. 

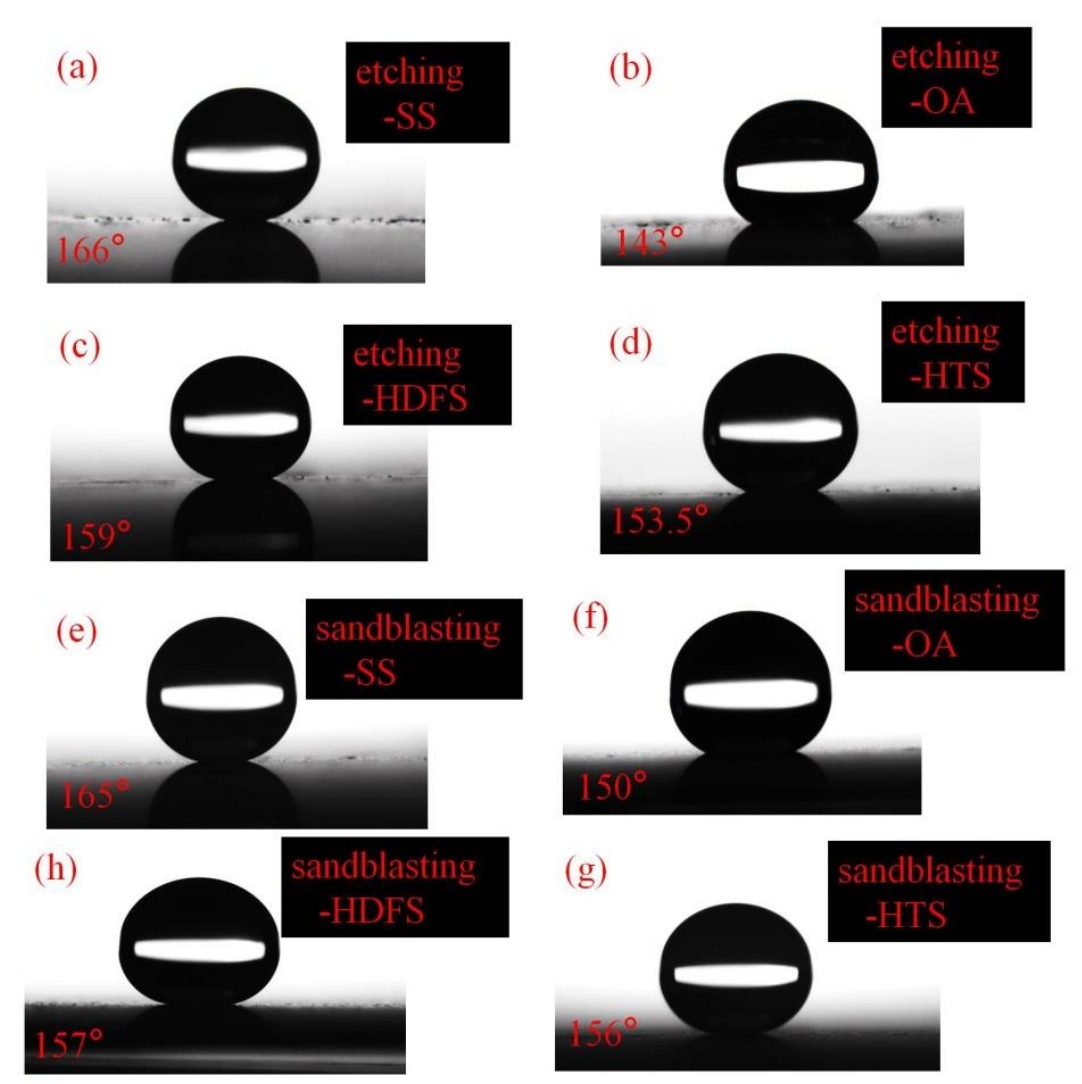

Fig.8. Water contact angle images of (a): etching-SS; (b): etching-OA; (c): etching-HDFS; (d): etching-HTS; (e): sandblasting-SS; (f): sandblasting-OA; (g): sandblasting-HDFS; (h): sandblastingHTS.

\section{Table 3}

The contact angles of the flat surfaces before and after being modified.

\begin{tabular}{cccccc}
\hline samples & flat aluminum & $\begin{array}{c}\text { flat aluminum } \\
\text { modified by } \\
\text { SS }\end{array}$ & $\begin{array}{c}\text { flat aluminum } \\
\text { modified by } \\
\text { OA }\end{array}$ & $\begin{array}{c}\text { flat aluminum } \\
\text { Modified by } \\
\text { HDFS }\end{array}$ & $\begin{array}{c}\text { flat aluminum } \\
\text { modified by } \\
\text { HTS }\end{array}$ \\
\hline SCA $\left(^{\circ}\right)$ & $89.4 \pm 3.0$ & $145 \pm 2.3$ & $92.4 \pm 2.5$ & $120.7 \pm 1.2$ & $105.1 \pm 2.0$ \\
\hline
\end{tabular}

In Table 2, it was observed that the SCA changed along with the roughness which was affected by the low surface energy materials. For the same method to prepare rough structures, compared to unmodified surfaces, the roughness of SS modified surfaces was increased, but that of OA modified surfaces was decreased. However the roughness of HTS or HDFS modified surfaces was similar to the un-modified surfaces. So the surfaces modified by SS (etching-SS, sandblasting-SS) had the largest contact angles of $166^{\circ}$ and $165^{\circ}$, respectively. The contact angles were only $143^{\circ}$ and $150^{\circ}$ for OA modified rough Al surfaces. The SCA on the surfaces modified by HTS or HDFS lied between the SS modified and OA modified surfaces. However, the values of SCA on the HDFS modified surfaces were larger than the HTS modified surfaces. The reason was that the surface energy of HDFS was lower than that of HTS. Further, according to Table 3, on the flat aluminum, the SCAs on the HDFS modified surface were larger than those on the HTS modified surface, which indicated that the surface energy of HDFS was lower than that of HTS. It testified that the roughness of the rough surfaces played a vital role in illustrating the superhydrophobic behavior, [41] however, the rough 
surfaces must be prepared by the same method. If the rough surfaces were made through different methods, the roughness was not a correct indicator to measure superhydrophobic behavior. Meanwhile, for the same roughing method, it was very important to choose which low surface energy material was used as the hydrophobic material to make the surface repelling water.

\subsection{Durability}

Up to now, the durability of superhydrophobic surfaces is still an obstacle to practical applications. Many researchers are working on this particular field to fabricate durable substrates [42, 20]. In this paper, we have prepared eight kinds of superhydrophobic surfaces using two roughing methods and four low surface energy materials to modify the rough surfaces. Through a sandpaper-abrasion experiment, we evaluated the durability of these rough superhydrophobic surfaces to find the best anti-wear rough surface. The modified rough $\mathrm{Al}$ plates were put on a $1500 \mathrm{CW}$ sandpaper with $10 \mathrm{~g}$ weights over the plates. Under the impetus of force, substrates moved slowly along with the ruler. The contact angles were tested after each abrasion, and the abrasion times were recorded. Table 2 listed the abrasion times of all the rough superhydrophobic surfaces. From Table 2, it could be found that the durability of the rough surface was proportional to the roughness of the surface. Fig. 9 showed the effect of abrasion on the wetting properties of the superhydrophobic aluminum surfaces.

It could be seen in Fig. 9 that the SS modified rough surfaces were more durable than the rough surfaces modified by other three kinds of modifiers. Since SS which included a mount of $\mathrm{SiO}_{2}$ particles stacked on the rough surfaces, it obviously enhanced the roughness of the rough $\mathrm{Al}$ surfaces. In the early stages of wear, the $\mathrm{SiO}_{2}$ nanoparticles acted as roller bearings, leading to decreased abrasive wear. The SS layer was much thicker than other low energy layers, which could be seen in the SEM and AFM testing section. Therefore more abrasion cycles were required to be removed. In addition, the SS layer consisted of $\mathrm{SiO}_{2}$ nanoparticles was with very high surface curvature and their aggregates increased the surface curvature for convex particles, which resulted in the contact angle increasing. Thus, even if some part of SS coating was frayed, the remaining particles with very high contact angles would still help to maintain the superhydrophobicity of the surface. When SS stacking on the rough surface was worn off, the protected Al rough surface was exposed to abrasion. The rough surfaces modified by HDFS or HTS had similar durability properties. They both formed covalent bonds with the modified surfaces and dispersed on the surface with monomolecular layers. The roughness of these substrate surfaces was enhanced slightly. When these surfaces were rubbed, the Al surfaces were directly exposed to abrasion, which were parallel to the SS modified surfaces after the SS stacking was worn off. So HDFS or HTS modified surfaces were less anti-wear than the SS modified surfaces. The surfaces modified by OA were the least durable surfaces. The OA molecules were just filled in the grooves on the surfaces rather than by covalent bonds with the substrates. The $R_{\mathrm{q}}$ values of the OA modified surfaces were decreased. When these surfaces were subjected to fray, the rough structures of $\mathrm{Al}$ surfaces were easily rubbed off and the superhydrophobicity was easily lost. When the contact angle was lower than $150^{\circ}$, the abrasion test was stopped. So the abrasion test was not performed on the surface etching-OA. From the values of $R_{\mathrm{q}}$ and the times of abrasion cycles, though the sandblasting-OA had larger $R_{\mathrm{q}}$ values than the etching-HDFS and etching-HTS surfaces, its times of abrasion cycles was less than the latter two. The contact angle of sandblasting-OA was only $150{ }^{\circ} \mathrm{C}$, so its superhydrophobicity was easily lost after abrasion. From Fig. 9, it also could be seen that the 
rough surfaces prepared by the second method were much durable than the first method prepared surfaces. The reason was that the second method prepared surfaces had higher values of $R_{\mathrm{q}}$ than the first method prepared surfaces. So when the surface had higher $R_{\mathrm{q}}$ values, its durable was better. This is in agreement with the conclusion that the enhanced roughness from the nanostructures formed on the microscale structures would improve the mechanical durability of superhydrophobic surface.[14,39]

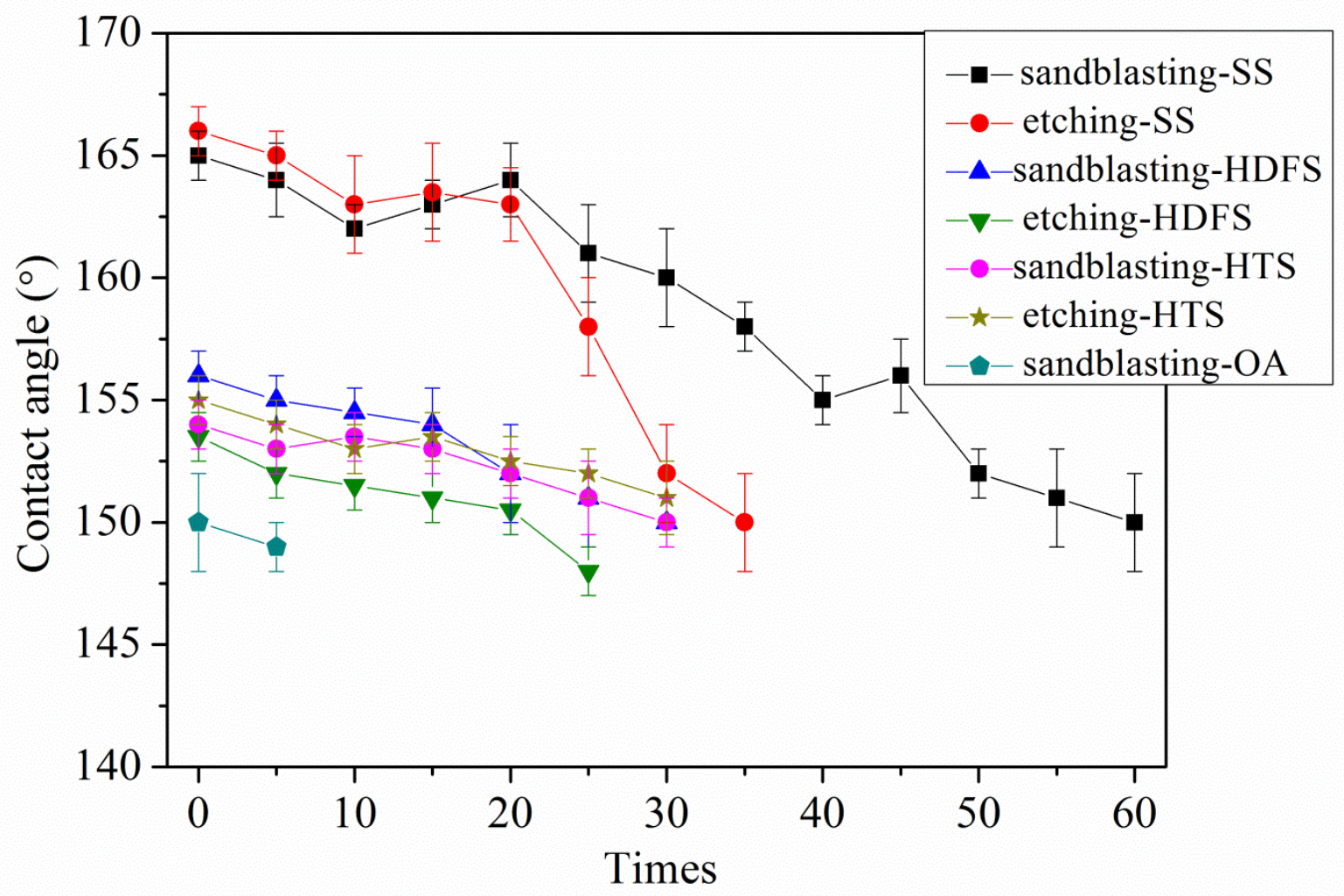

Fig.9. Water contact angles of the superhydrophobic surfaces versus the abrasion cycles.

The pencil hardness test was conducted as follow [13]: a pencil with quantified hardness was pressed firmly on the surfaces while moving along the surface at a constant speed. The pencil was formed a 45 degree angle with the surface. The test was carried out on the surfaces before and after being exposed in the open air for 7 months. The results were listed in Table 4 . If a thin film was coated on a substrate by van der Waals interactions, it usually could not endure 1B pencil hardness tests. A good index of performance for a durable superhydrophobic surface was at least $2 \mathrm{H}$. From Table 4, it could be concluded that OA was grafted on the surfaces by van der Waals interactions, which was in accordance to the XPS result that OA molecules did not form covalent bonds with the surfaces. The surfaces modified by HDFS or HTS were durable due to the covalent bonds between the HDFS/HTS molecules and the surfaces. As the $\mathrm{SiO}_{2}$ nanoparticles act as roller bearings, the durability of SS modified surfaces was higher than others. 
However, from the wettability of the surfaces exposed outdoor for 7 months, the HDFS modified surfaces had higher SCA and lower SA than other candidates. It may be the reason that the surface energy of HDFS was lower than others.

\section{Table 4}

6 The hardness and wettability tests on the surfaces

\begin{tabular}{lllll}
\hline samples & Hardness $^{\mathrm{a}}$ & Hardness $^{\mathrm{b}}$ & $\mathrm{SCA}^{\mathrm{b}}\left(^{\circ}\right)$ & $\mathrm{SA}^{\mathrm{b}}\left(^{\circ}\right)$ \\
\hline etching-SS & $3 \mathrm{H}$ & $\mathrm{H}$ & $135.8 \pm 1.5$ & $20 \pm 1.0$ \\
etching-OA & $2 \mathrm{~B}$ & $<2 \mathrm{~B}$ & $44.3 \pm 2.3$ & $>20$ \\
etching-HDFS & $2 \mathrm{H}$ & $\mathrm{H}$ & $150.8 \pm 2.0$ & $9 \pm 0.3$ \\
etching-HTS & $2 \mathrm{H}$ & $\mathrm{HB}$ & $144.5 \pm 2.1$ & $10.5 \pm 0.5$ \\
sandblasting-SS & $6 \mathrm{H}$ & $4 \mathrm{H}$ & $151.5 \pm 1.3$ & $7.8 \pm 0.5$ \\
sandblasting-OA & $2 \mathrm{~B}$ & $<2 \mathrm{~B}$ & $91 \pm 1.7$ & $>20$ \\
sandblasting- & $5 \mathrm{H}$ & $2 \mathrm{H}$ & $154.1 \pm 2.3$ & $5 \pm 0.5$ \\
HDFS & & & & \\
sandblasting-HTS & $5 \mathrm{H}$ & $3 \mathrm{H}$ & $150.6 \pm 1.6$ & $8.5 \pm 0.3$ \\
\hline
\end{tabular}

a the thin film before exposed outdoor for 7 months

b the thin film after exposed outdoor for 7 months

\section{Conclusions}

In summary, two methods were used to build different rough structures, and four low surface energy materials were respectively used to modify the rough substrates through solution immersion method. After abrasion tests, the durability was investigated. Conclusions were drawn as follows: (a) when SS that included some amount of $\mathrm{SiO}_{2}$ was used to modify the rough surfaces, $\mathrm{SS}$ could coat on almost all areas of the Al surfaces. Hence, the roughness of the surfaces was increased greatly. (b) When HDFS or HTS was used to modify the rough surfaces, the HDFS or HTS molecules would form covalent bonds with $\mathrm{Al}$ surfaces and they were dispersed on the substrates in monomolecular layers. So the roughness of these surfaces was changed slightly. (c) When OA was used to modify the rough surfaces, the OA molecules filled in the grooves of the rough surfaces by physical effect. So the roughness of the surfaces was reduced. (d) When the surfaces had larger roughness, they would be more durable. So the SS modified surfaces that were prepared by the second method were the best durability surfaces. It provided a direction for the fabrication of promising durable super-hydrophobic surfaces.

\section{Acknowledgements}

This Project was supported by the National Science Fund for Distinguished Young Scholars of China, No. 51425601. It was also supported by Natural Science Foundation of China, No. 51376064; and by the National Key Research and Development Program, No. 2016 YFB0901404.

\section{References}


[1] Z. Han, H. Guan, Y. Cao, S. Niu, L. Ren, Antifogging properties and mechanism of micron structure in Ephemera pictiventris McLachlan compound eyes, Chin. Sci. Bull. 59 (2014) 2039-2044. [2] Y. Chen, Y. Zhang, L. Shi, J. Li, Y. Xin, T. Yang, Z. Guo, Transparent superhydrophobic/superhydrophilic coatings for self-cleaning and anti-fogging, Appl. Phys. Lett. 101 (2012) 033701 (033701-033704).

[3] A. Tricoli, M. Righettoni, S.E. Pratsinis, Anti-Fogging nanofibrous $\mathrm{SiO}_{2}$ and nanostructured $\mathrm{SiO}_{2}$ $\mathrm{TiO}_{2}$ films made by rapid flame deposition and in situ annealing, Langmuir 25 (2009) 12578-12584. [4] S. Zheng, C. Li, Q. Fu, W. Hu, T. Xiang, Q. Wang, M. Du, X. Liu, Z. Chen, Development of stable superhydrophobic coatings on aluminum surface for corrosion-resistant, self-cleaning, and anti-icing applications, Mater. Design. 93 (2016) 261-270.

[5] Z. Zhang, B. Ge, X. Men, Y. Li, Mechanically durable, superhydrophobic coatings prepared by dual-layer method for anti-corrosion and self-cleaning, Colloid. Surface. A 490 (2016) 182-188.

[6] P.S. Brown, B. Bhushan, Mechanically durable, superomniphobic coatings prepared by layer-bylayer technique for self-cleaning and anti-smudge, J. Colloid. Interface. Sci. 456 (2015) 210-218.

[7] S. Peng, B. Bhushan, Mechanically durable superoleophobic aluminum surfaces with microstep and nanoreticula hierarchical structure for self-cleaning and anti-smudge properties, J. Colloid. Interface. Sci. 461 (2016) 273-284.

[8] J. Li, R. Wu, Z. Jing, L. Yan, F. Zha, Z. Lei, One-step spray-coating process for the fabrication of colorful superhydrophobic coatings with excellent corrosion resistance, Langmuir 31 (2015) 1070210707.

[9] S. Ammar, K. Ramesh, B. Vengadaesvaran, S. Ramesh, A. Arof, Amelioration of anticorrosion and hydrophobic properties of epoxy/PDMS composite coatings containing nano ZnO particles, Prog. Org. Coat. 92 (2016) 54-65.

[10] M.A. Sarshar, C. Swarctz, S. Hunter, J. Simpson, C.H. Choi, Effects of contact angle hysteresis on ice adhesion and growth on superhydrophobic surfaces under dynamic flow conditions, Colloid. Polym. Sci. 291 (2013) 427-435.

[11] P. Kim, T.S. Wong, J. Alvarenga, M.J. Kreder, W.E. Adorno Martinez, J. Aizenberg, Liquidinfused nanostructured surfaces with extreme anti-ice and anti-frost performance, ACS nano 6 (2012) 6569-6577.

[12] A. Cassie, S. Baxter, Wettability of porous surfaces, Trans. Faraday Soc. 40 (1944) 546-551.

[13] A. Milionis, E. Loth, I.S. Bayer. Recent advances in the mechanical durability of superhydrophobic materials. Adv Colloid Interfac. 229(2016) 57-79.

[14] C.H. Xue, J.Z. Ma, Long-lived superhydrophobic surfaces, J. Mater. Chem. A. 1(2013) 41464161.

[15] S. Peng, D. Tian, X. Yang, W. Deng, Highly efficient and large-scale fabrication of superhydrophobic alumina surface with strong stability based on self-congregated alumina nanowires, ACS Appl. Mater. Inter. 6 (2014) 4831-4841.

[16] Y.Y. Zhang, Q. Ge, L.L. Yang, X.J. Shi, J.J. Li, D.Q. Yang, E. Sacher, Durable superhydrophobic PTFE films through the introduction of micro- and nanostructured pores, Appl. Surf. Sci. 339 (2015) 151-157.

[17] H. Cho, D. Kim, C. Lee, W. Hwang, A simple fabrication method for mechanically robust superhydrophobic surface by hierarchical aluminum hydroxide structures, Curr. Appl. Phys 13 (2013) $762-767$. 
[18] L.R. Scarratt, B.S. Hoatson, E.S. Wood, B.S. Hawkett, C. Neto, Durable superhydrophobic surfaces via spontaneous wrinkling of Teflon AF, ACS Appl Mater Interfaces 8 (2016) 6743-6750.

[19] P. Vengatesh, M.A. Kulandainathan, Hierarchically ordered self-lubricating superhydrophobic anodized aluminum surfaces with enhanced corrosion resistance, ACS Appl Mater Interfaces 7 (2015) 1516-1526.

[20] L. Xu, Z. Geng, J. He, G. Zhou, Mechanically robust, thermally stable, broadband antireflective, and superhydrophobic thin films on glass substrates, ACS Appl Mater Interfaces 6 (2014) 9029-9035. [21] D. Lv, J. Ou, M. Xue, F. Wang, Stability and corrosion resistance of superhydrophobic surface on oxidized aluminum in $\mathrm{NaCl}$ aqueous solution, Appl. Surf. Sci. 333 (2015) 163-169.

[22] Y.Y. Quan, L.Z. Zhang, Facile fabrication of superhydrophobic films with fractal structures using epoxy resin microspheres, Appl. Surf. Sci. 292 (2014) 44-54.

[23] Y.Y. Quan, P.G. Jiang, L.Z. Zhang, Development of fractal Ultra-hydrophobic coating films to prevent water vapor dewing and to delay frosting, Fractals 22 (2014) 1440002.

[24] S. Lee, W. Kim, S. Lee, S. Shim, D. Choi, Controlled transparency and wettability of large-area nanoporous anodized alumina on glass, Scripta Mater. 104 (2015) 29-32.

[25] J. Zimmermann, F.A. Reifler, G. Fortunato, L.C. Gerhardt, S. Seeger, A simple, one-step approach to durable and robust superhydrophobic textiles, Adv. Funct. Mater. 18 (2008) 3662-3669. [26] L. Yin, J. Yang, Y. Tang, L. Chen, C. Liu, H. Tang, C. Li, Mechanical durability of superhydrophobic and oleophobic copper meshes, Appl. Surf. Sci. 316 (2014) 259-263. [27] P. Li, X. Chen, G. Yang, L. Yu, P. Zhang, Fabrication and characterization of stable superhydrophobic surface with good friction-reducing performance on Al foil, Appl. Surf. Sci. 300 (2014) 184-190.

[28] R.P. Netterfield, P. Martin, C. Pacey, W. Sainty, D. McKenzie, G. Auchterlonie, Ion-assisted

[29] D. Sprenger, H. Bach, W. Meisel, P. Gütlich, XPS study of leached glass surfaces, J. Non-Cryst. Solids 126 (1990) 111-129.

[30] W. Zhang, W. Liu, C. Wang, Characterization and tribological investigation of sol-gel $\mathrm{Al}_{2} \mathrm{O}_{3}$ and doped $\mathrm{Al}_{2} \mathrm{O}_{3}$ films, J. Eur. Ceram. Soc. 22 (2002) 2869-2876.

[31] F. Cemin, L.T. Bim, L.M. Leidens, M. Morales, I.J. Baumvol, F. Alvarez, C.A. Figueroa, Identification of the chemical bonding prompting adhesion of a-C:H thin films on ferrous alloy intermediated by a SiC $\mathrm{x}: \mathrm{H}$ buffer layer, ACS Appl Mater Interfaces 7 (2015) 15909-15917.

[32] W. Zhang, W. Liu, C. Wang, Characterization and tribological investigation of sol-gel $\mathrm{Al}_{2} \mathrm{O}_{3}$ and doped $\mathrm{Al}_{2} \mathrm{O}_{3}$ films, J. Eur. Ceram. Soc. 22 (2002) 2869-2876.

[33] D. Kumar, X. Wu, Q. Fu, J.W.C. Ho, P.D. Kanhere, L. Li, Z. Chen, Development of durable selfcleaning coatings using organic-inorganic hybrid sol-gel method, Appl. Surf. Sci. 344 (2015) 205212.

[34] S.Z. Chen, P.Y. Zhang, W.P. Zhu, L. Chen, S.M. Xu, Deactivation of $\mathrm{TiO}_{2}$ photocatalytic films loaded on aluminium: XPS and AFM analyses, Appl. Surf. Sci. 252 (2006) 7532-7538.

[35] N. Saleema, D.K. Sarkar, R.W. Paynter, X.G. Chen, Superhydrophobic aluminum alloy surfaces by a novel one-step process, ACS Appl Mater Interfaces 2 (2010) 2500-2502.

[36] Y. Liu, J. Liu, S. Li, J. Liu, Z. Han, L. Ren, Biomimetic superhydrophobic surface of high adhesion fabricated with micronano binary structure on aluminum alloy, ACS Appl Mater Interfaces 5 (2013) 8907-8914. 
1 [37] N.Y. Cui, C. Liu, N.M.D. Brown, B.J. Meenan, An exploratory study of the effects of the 2 dielectric-barrier-discharge surface pre-treatment on the self-assembly processes of a (33 Aminopropyl) trimethoxysilane on glass substrates, Appl. Surf. Sci. 253 (2007) 6932-6938.

4 [38] L. Boinovicn, A. Emelyanenko, The prediction of wettability of curved surfaces on the basis of 5 the isotherms of the disjoining pressure, Colloids and Surfaces A: Physicochem. Eng. Aspects. 383 6 (2011) 10-16.

7 [39] T. Verho, C. Bower, P. Andrew, S. Franssila, O. Ikkala, R.H. Ras, Mechanically durable 8 superhydrophobic surfaces, Adv. Mater. 23 (2011) 673-678.

9 [40] A.M. Emelyanenko, F.M. Shagieva, A.G. Domantovsky, L.B. Boinovich. Nanosecond laser 10 micro- and nanotexturing for the design of asuperhydrophobic coating robust against long-term 11 contact withwater, cavitation, and abrasion. Appl. Surf. Sci. 332(2015) 513-517.

12 [41] L. Mammen, X. Deng, M. Untch, D. Vijayshankar, P. Papadopoulos, R.d. Berger, E. Riccardi, 13 F.d.r. Leroy, D. Vollmer, Effect of nanoroughness on highly hydrophobic and superhydrophobic 14 coatings, Langmuir 28 (2012) 15005-15014.

15 [42] V. Kondrashov, J. Ruhe, Microcones and nanograss: toward mechanically robust 16 superhydrophobic surfaces, Langmuir 30 (2014) 4342-4350. 
2 Table 1 Atomic percentages of bare Al, rough Al before and after modified.

3 Table 2 Effects of roughness on wettability and durability.

4 Table 3 The contact angles of the flat surfaces before and after being modified.

5 Table 4 The hardness and wettability tests on the surfaces.

6 Figure Captions

7 Fig.1. The schematic of sandpaper-abrasion test.

Fig.2. SEM images of (a): bare $\mathrm{Al}$; (b): microstructural $\mathrm{Al}$ obtained by sandblasting; (c): microstructural $\mathrm{Al}$ obtained by $\mathrm{NaClO}$ etching; (d): hierarchical structure obtained by sandblasting combined with wet chemical etching (the amplified picture was inserted into the upper right corner); (e): hierarchical structure obtained by two-step chemical etching (the nanostructures were depicted in the upper right corner).

Fig.3. XPS survey spectra of (a): etched rough Al surfaces; (b): rough Al surfaces modified by SS; (c): rough Al surfaces modified by OA; (d): rough Al surfaces modified by HDFS; (e): rough Al surfaces modified by HTS. In the images, etching meant the rough Al surfaces were prepared by chemical etched and sandblasting meant the rough $\mathrm{Al}$ surfaces were made by sandblast.

Fig.4. Deconvoluted XPS spectra of different chemical modification technologies on the two kinds of rough surfaces (etching and sandblasting). SS: (a) O 1s and (b) Si 2p; OA: (c) O 1s and (d) Al 2p; HDFS: (e) O 1s and (f) Si 2p; HTS: (g) O 1s and (h) Si 2p.

Fig.5. SEM images showing the structures of (a): etching-SS; (b): etching-OA; (c): etching-HDFS; (d): etching-HTS; (e): sandblasting-SS; (f): sandblasting-OA; (g): sandblasting-HDFS; (h): sandblasting- HTS.

Fig.6. AFM plane images and 3D images of the rough Al surfaces made by etching-method before and after modification. (a) and (i): etching; (b) and (ii): etching-SS; (c) and (iii): etching-OA; (d) and (iv): etching-HDFS; (e) and (v): etching-HTS. The roughness parameters were achieved by profile extraction of topographical images. Scan area $5 \times 5 \mu \mathrm{m} 2$.

Fig.7. AFM plane images and 3D images of the rough Al surfaces made by sandblasting-method before and after modification. (a) and (i): sandblasting; (b) and (ii): sandblasting-SS; (c) and (iii): sandblasting-OA; (d) and (iv): sandblasting-HDFS; (e) and (v): sandblasting-HTS. The 

$5 \times 5 \mu \mathrm{m} 2$.

3 Fig.8. Water contact angle images of (a): etching-SS; (b): etching-OA; (c): etching-HDFS; (d): etching-HTS; (e): sandblasting-SS; (f): sandblasting-OA; (g): sandblasting-HDFS; (h): sandblasting-HTS.

6 Fig.9. Water contact angles of the superhydrophobic surfaces versus the abrasion cycles. 